\title{
Two unrecorded naturalized plants in Korea: Stachys agraria and Dracocephalum moldavica (Lamiaceae)
}

\author{
Keum Seon Jeong, Chang-Seok Jang, Soo Hyun Park, Jung Sim Lee, Suk Min Yoon ${ }^{1}$, \\ Tae Hwan Kim², Chang Ho Shin and Kyung Choi* \\ Department of Forest Biodiversity and Herbarium, Korea National Arboretum, Pocheon 11186, Korea \\ ${ }^{1}$ National Environment Division, Han River Basin Environmental office, Hanam 12902, Korea \\ ${ }^{2}$ Gonghang-daero, Seoul, 07570 Korea
}

(Received 22 November 2016; Revised 30 November 2016; Accepted 12 December 2016)

\author{
한반도 미기록 귀화식물: 애기석잠풀과 향용머리 \\ 정금선 · 장창석 · 박수현 · 이정심 · 윤석민 ${ }^{1} \cdot$ 김태환 $^{2}$ · 신창호 · 최경* \\ 국립수목원 산림생물조사과'한강유역환경청 환경관리국 자연환경과 \\ 2서울 양천구 공항대로
}

\begin{abstract}
Two unrecorded naturalized species, Stachys agraria Schltdl. \& Cham. and Dracocephalum moldavica L (Lamiaceae), are newly reported in Korea. Stachys agraria and D. moldavica were found at Seogwipo-si on Jeju-do and at ChunChen-si in Gangwondo in Korea, respectively. Stachys agraria is distinguished from other related Korean taxa by corolla of 2.4-5.2 mm long with six to twelve flowers in the node. Its local name is "Ae-gi-seok-jam-pul" based on shorter than longer corollar. Dracocephalum moldavica was distinguishable from other Dracocephalum in Korea by the following combination of characters, oblong to ovate-triangular $(1.7-2.4 \mathrm{~cm} \times 0.8-1.2 \mathrm{~cm})$ leaves and rough crenate at the margin. This taxon is referred to as 'Hyang-yong-meo-ri' in Korean based on its fragrance. We provide a description, illustrations, photographs, and a key of related taxa in Korea.
\end{abstract}

Keywords: Stachys agraria, Dracocephalum moldavica, Lamiaceae, naturalized plants

적 요: 꿀풀과 석잠풀속 애기석잠풀과 용머리속 향용머리 2종을 제주특별시 서귀포시와 강원도 춘천시에서 각각 발견하여 한국 미기록 귀화식물로 보고한다. 애기석잠풀은 화관의 길이가 $2.4-5.2 \mathrm{~mm}$ 이고, 꽃은 6-12개로 한반도에 분포하는 석잠풀속 다른 분류군과 구별된다. 이 분류군의 국명은 꽃의 크기가 작은 특징으로 '애기석 잠풀’로 명명하였다. 용머리속 미기록 귀화식물은 잎이 주걱형 혹은 타원형이고, 가장자리에 무딘 톱니형의 거 치가 있어 속내 근연종들과 뚜렷하게 구별된다. 본 분류군은 향기가 강하게 나는 특징을 고려하여 ‘향용머리'로 국명을 신칭하였다. 미기록 귀화식물 2 분류군에 대한 기재, 도해, 사진 및 검색표를 제시하였다.

주요어: 애기석잠풀, 향용머리, 꿀풀과, 미기록 귀화식물

꿀풀과(Lamiaceae)는 전 세계적으로 205속 6,700여종 이 상이 분포하고 있으며, 식용, 약용, 관상용 등의 중요한 경 제적 가치를 가진 종들이 많이 포함되어 있는 주요 과 (family) 중에 하나이다(Cronquist, 1981; Judd et al., 2008). 한국에 분포하는 꿀풀과는 26속 65 분류군이다(Suh et al, 2007).

\footnotetext{
*Author for correspondence: kchoi69@korea.kr
} 
A

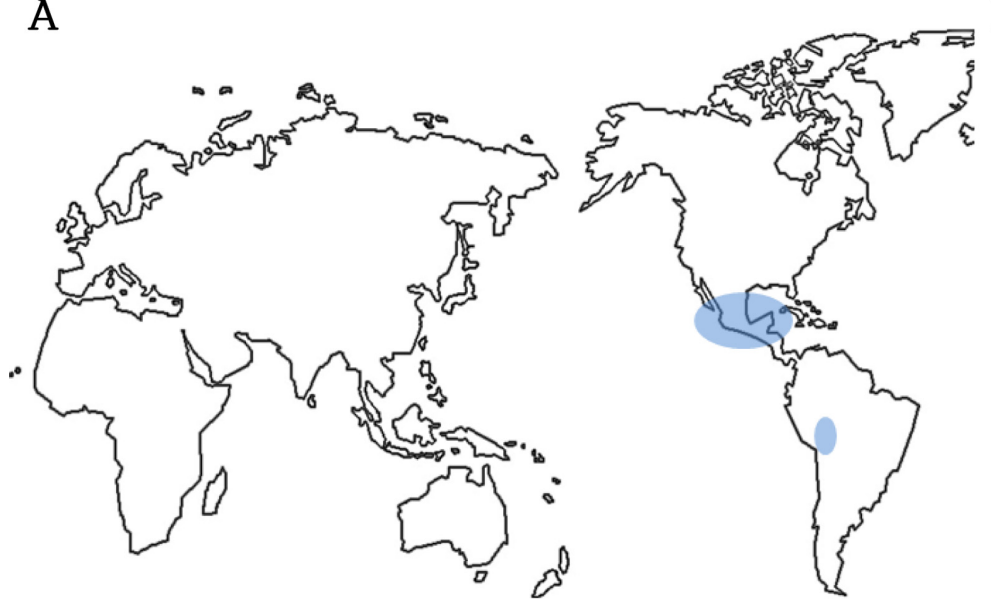

B

C

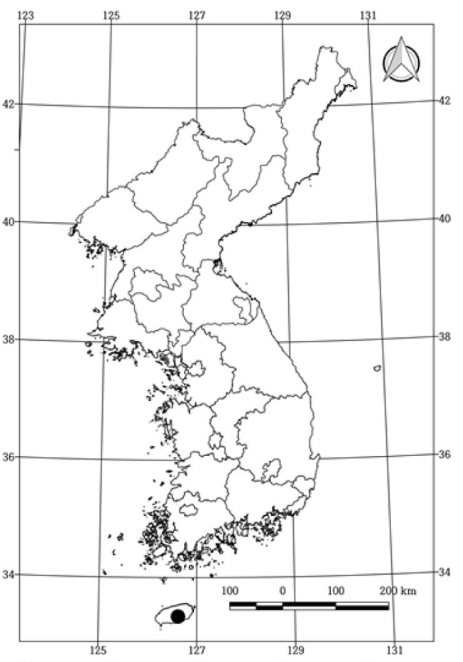

$\mathrm{D}$

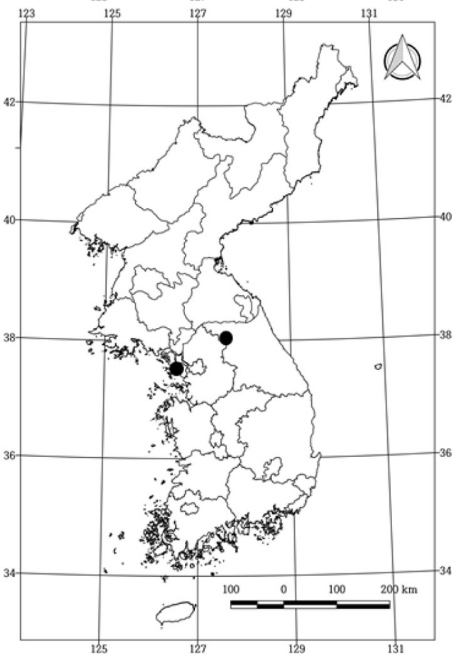

Fig. 1. Distribution of Stachys agraria (A, B) and Dracocephalum moldavica (C, D) (left, global distribution; right, new collected site from Korea).

석잠풀속(Stachys L.)은 약 300 여종이 포함된 꿀풀과의 큰 속으로 오스트리아와 뉴질랜드를 제외한 전 세계적으 로 분포하고 있으며(Bhattacharjee, 1980; Harley et al., 2004), 한국에는 석잠풀(Stachys japonica Miq.), 우단석잠 풀(Stachys oblongifolia Benth.)을 비롯하여 4종이 분포하 고 있다(Lee, 1999). 용머리속(Dracocephalum L.)은 약 70 여 분류군이 아시아를 중심으로 전 세계적으로 분포하며 관상적 가치가 높아 많은 지역에서 재배하고 있다(Fig. 1). 한국에 분포하는 용머리속 식물은 용머리(Dracocephalum argunense Fisch. ex Link)와 주로 고산지대에 분포 하는 벌깨풀(Dracocephalum rupestre Hance) 2 분류군이 알 려져 있다(Lee, 1999).

본 연구에서는 제주특별시 서귀포시 표선면 일대에서 확인된 석잠풀속 및 인천광역시와 강원도 춘천시 일대에 서 관찰된 용머리속 귀화식물 2 분류군에 대하여 외부형 태학적 형질을 기재하며 도해도 및 화상 자료를 제공하고 근연분류군과의 검토를 통해 검색표를 제시하였다.

\section{분류군의 기재}

Stachys agraria Schltdl. \& Cham., Linnaea 5: 100, 1830. -TYPE: Mexico, Prope la Joya, Jun 1829 (holotype: HAL), seen as photo.

Stachys crenata Raf., Fl. Ludov 42, 1817.

Stachys confusa Briq., Jard. Bot. Genève 2: 122, 1898.

Stachys camporum M. E. Jones, Contr. W. Bot. 12: 70, 1908.

Plants annual, biennial or perennial branched herbs with basal rudimentary leaves. Stems thin, $10-45 \mathrm{~cm}$ long, simple or branched, usually erect, rarely procumbent; internodes 2$5 \mathrm{~cm}$ long; sparsely covered by short simple papillate hairs up to $2 \mathrm{~mm}$. Leaves ovate-oblong to elliptic, $5-15 \mathrm{~mm} \times 0.8-$ $1.2 \mathrm{~cm}$, margin evenly serrate; obtuse at apex, usually attenuate or rarely cordate at base, hairy as the stem, petiole $1-2.5 \mathrm{~cm}$ long. Inflorescence with petiolate to subsessile bracts, ovate to 

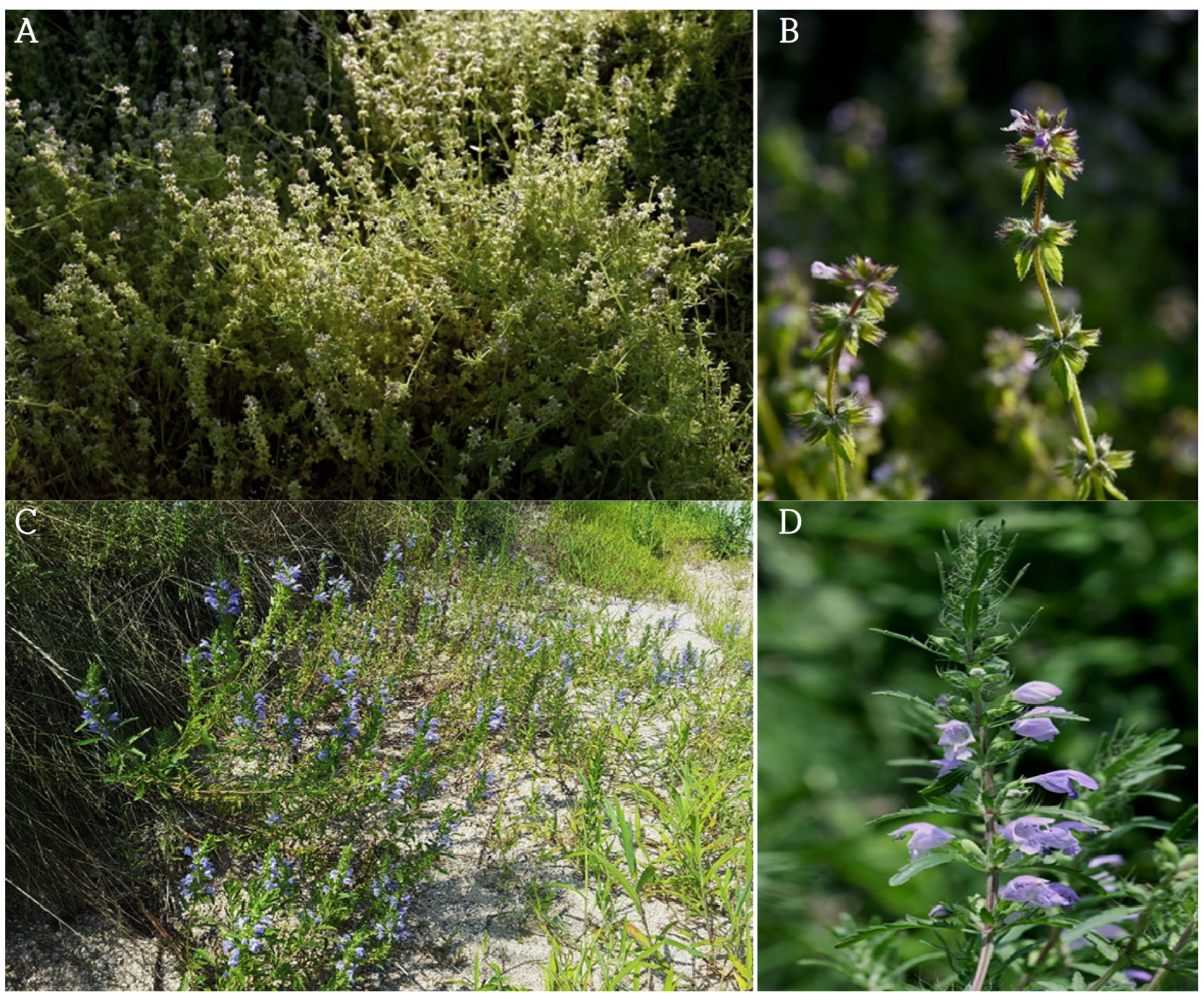

Fig. 2. Photographs of Stachys agraria (A, B) and Dracocephalum moldavica (C, D) (A, C, Habitat; B, D, Inflorescence).

ovate-lanceolate, $0.7-2.0 \times 0.4-0.6 \mathrm{~cm}$, weakly crenate or entire at margin, without glandular-capitate, subsessile to sessilethe lowest leafy, the others reduced, usually equaling or longer than sepals. Verticillasters six to twelve flowered in the node; pedicels $0.6-1.6 \mathrm{~mm}$ long; bracteoles few, linear to setaceous, herbaceous, 1.0-2.5 mm long. Calyx bilabiate, tubular, nearly actinomorphic, gibbous at base, 4.0-5.0(-5.5) mm long; teeth subequal, $2.5-4.0 \mathrm{~mm}$ long, triangular-subulate to lanceolate, erect to subrecurved, hispidulous, puberulent hairs outside, interior surface of calyx teeth hirsute and with pilose hairs inside, rest glabrous, covered with papillate short simple or long hairs at margin. Corolla medium red purple, sometimes white, 2.4-5.2 $\mathrm{mm}$ long, the tube not exserted from calyx, annulate or hemi-annulate inside toward base upper corolla lip 1-2.2 mm long; lower lip 2-4.8 mm long; filaments filiform, glabrous; anther 2-locule, elliptical, parallel. Pistil 1; ovary 4- locule; style gynobasic, 3.9-5.2 mm long, exserted, 2-cleft at apex. Nutlets $1-1.5 \mathrm{~mm}$ long and wide, broadly obovate, smooth, balckish brown (Figs. 2, 3).

Korean name: Ae-gi-seok-jam-pul (애기석잠풀).

Flowering: Mar to May.

Distribution: South America, Korea.

Korea: Jeju-do.

Specimens examined: KOREA. Jeju-do: Seogwipo-si, 2 Jun 2016, S. H. Park, 161001 (KH [2 sheets]); Seogwipo-si, 30 Apr 2016, J. S. Lee s.n. (KH).

\section{근연분류군과의 검색표}

1. Corolla tube and calyx (including teeth) less than $5.2 \mathrm{~mm}$ long S. agraria 애기석잠풀

1. Corolla tube mostly more than $7 \mathrm{~mm}$ long, calyx 

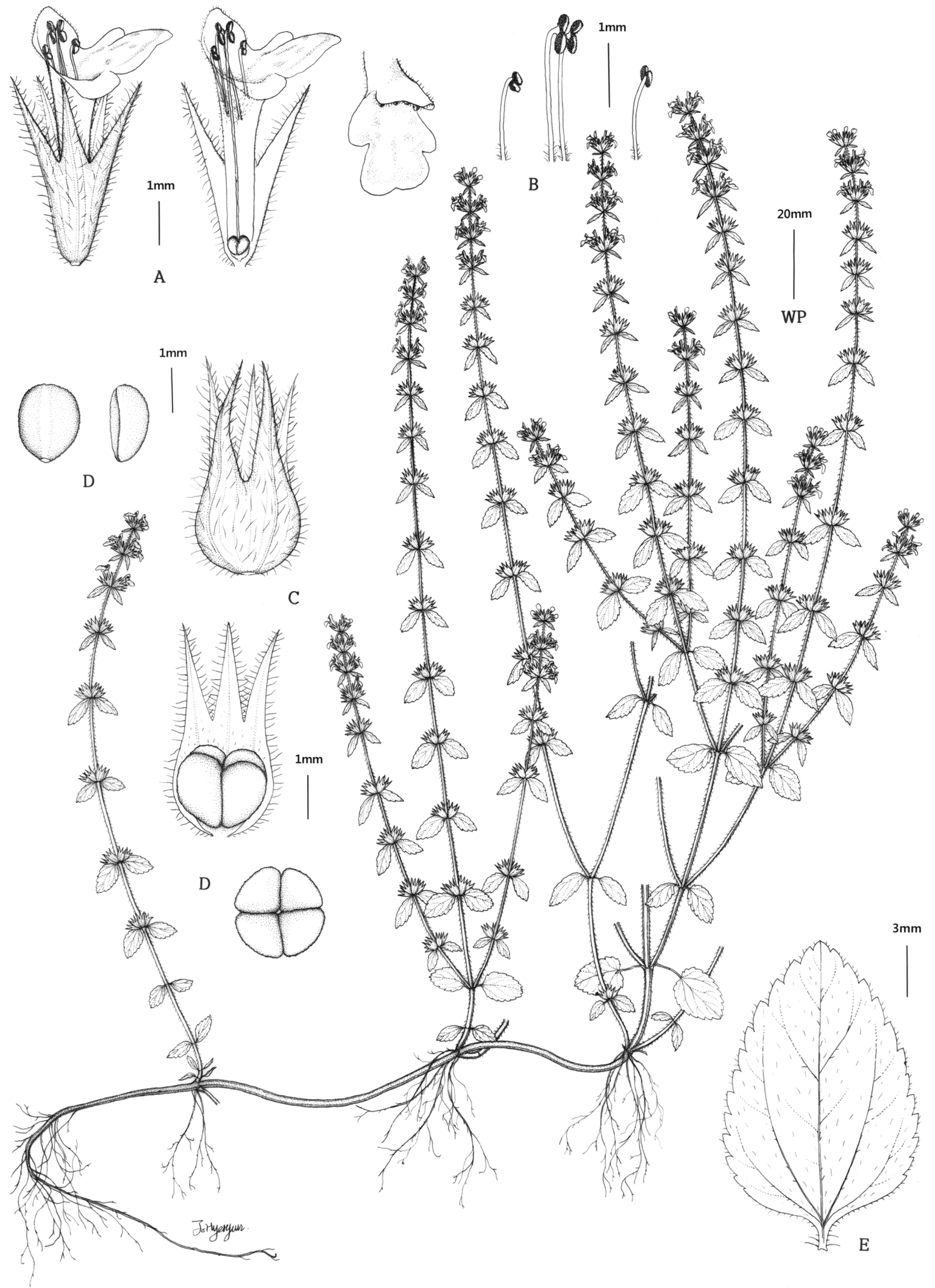

Fig. 3. Stachys agraria with a flowering inflorescence and leaves on stem. A. Flower. B. Stamen. C. Calyx. D. Seed. E. Leaf. 


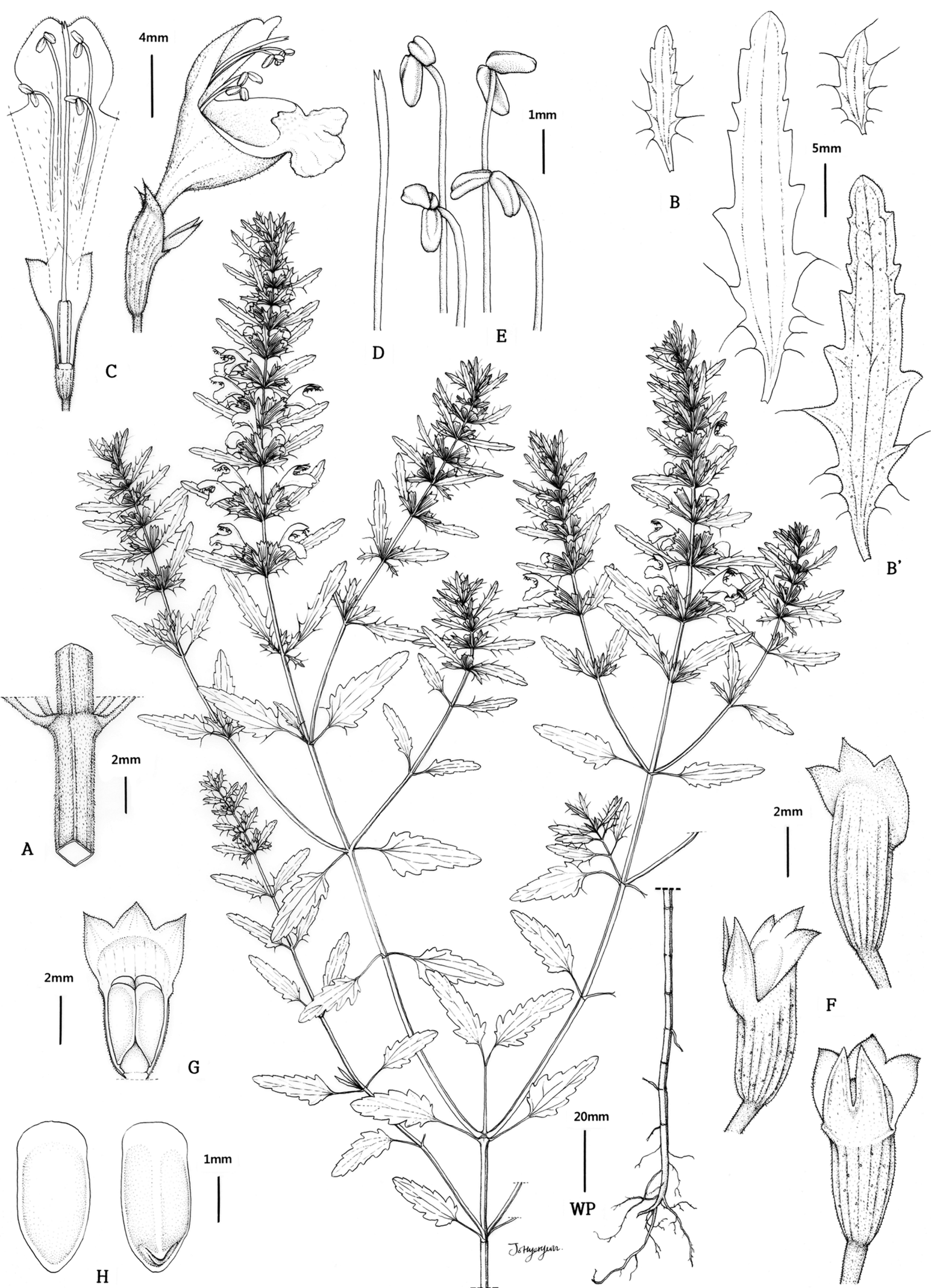

Fig. 4. Dracocephalum moldavica with a flowering inflorescence and leaves on stem. A. Stem. B, B'. Leaf. C. Flower. D. Style. E. Stamen. F. Calyx. G. Calyx cross section. H. Seed. 
(including teeth) more than $7 \mathrm{~mm}$ long …….............. 2 .

2. Leaves lanceolate to oblong-lanceolate, abaxial leaf surface densely gray villous-tomentose, veins villous S. oblongifolia 우단석잠풀

2. Leaves oblong to oblong-lanceolate, abaxial leaf surface puberulent to hispid or glabrous

S. japonica 석잠풀

Dracocephalum moldavica L., Sp. Pl. 2: 595, 1753.TYPE: Russia, Altai (holotype: PH), seen as photo.

Plants annual, branched herbs, Stems numerous. (6-)22$45 \mathrm{~cm}$ long, simple or branched, usually erect or ascending; internodes $3-4.7 \mathrm{~cm}$ long; sparsely covered by short minutely retrorse hairy hairs, purplish. Leaves basal cauline leaves withering early, oblong to ovate-triangular, $1.7-2.4 \mathrm{~cm}$ long $0.8-1.2 \mathrm{~cm}$ width, margin crenate to dentate; obtuse at apex, usually attenuate or rarely cordate at base, on both surfaces with a short eglandular indumentum, petiole as long as blade, $1.2-1.8 \mathrm{~cm}$ long, shorter upward; upper blades lanceolate to linear-lanceolate, $1.4-2.1 \mathrm{~cm}$ long $0.4-0.9 \mathrm{~cm}$ width, yellow glandular, sparsely minute hairy on vein, apex obtuse, base rounded to broadly cuneate, margin triangular-dentate or sparsely serrate, with basal teeth sometimes spinescentdenticulate, with spines. Inflorescence with petiolate to subsessile bracts, oblong to lanceolate, $0.2-0.8 \mathrm{~cm}$ long $0.1-$ $0.5 \mathrm{~cm}$ width, weakly crenate at margin with spines, usually equaling or longer than sepals, sparsely appressed hairy. Verticillasters six flowered in the node, loose, in 5-12 upper nodes of stems and branches; pedicels $3-5 \mathrm{~mm}$ long, horizontal after anthesis; Calyx bilabiate, tubular, nearly actinomorphic, gibbous at base, 7-10 $\mathrm{mm}$ long, golden glandular, pubescent especially basally, purple veined, 2-lipped to $2 / 3$ its length, teeth unequal, 1.5-2.5 mm long; upper lip 3 teeth divisions $1 /$ $4-1 / 3$ of lip, teeth subequal, triangular-ovate, apex acute; loewr lip 2-lipped, lanceolate mucronate teeth, hispidulous, puberulent hairs outside, interior surface of calyx teeth hirsute and with pilose hairs inside, rest glabrous. Corolla medium bluish purple, 1.5-2.5(-3.2) mm long, dilated beyond throat, the tube exserted from calyx, white pubescent outside annulate or hemi-annulate inside toward base upper lip short navicular, ca. 1/4 as long as tube; lower lip 3.8-5.2 mm long, middle lobe of lower lip dark purple spotted; filaments filiform, glabrous; anther 2-locule, elliptical, parallel. Pistil 1; ovary 4locule; style gynobasic, 3.9-5.2 mm long, exserted, 2-cleft at apex. Nutlets 1.8-2.3 mm long and wide, oblong, apex truncate, with a prominent V-shaped attachment scar, smooth, balckish brown(Figs. 2, 4).
Korean name: Hyang-yong-meo-ri (향용머리).

Flowering: Jun to Aug.

Distribution: China, Nei Mongol, Korea, Russia, Tajikistan, Turkmenistan (sometimes cultivated.); Eurasia, South America.

Korea: Gyeonggi-do, Gangwon-do.

Specimens examined: KOREA. Incheon, 16 Jul 2009, S. M. Yoon, YSM100 (KH). Gangwon-do: Chunchen-si, 23 Aug 2016, S. H. Park \& C. S. Jang 161444 (2 sheets, KH).

\section{근연분류군과의 검색표}

1. Leaves margin entire. …………. D. argunense 용머리

1. Leaves serrate or dentate. ……………………........... 2 .

2. Calyx 2-lipped to ca. $1 / 2$ its length corolla $1.5-2.5$ (3) $\mathrm{cm}$, dilated beyond throat, white pubescent outside; upper lip short navicular, ca. 1/4 as long as tube; Leaves base rounded to broadly cuneate, densely dentate with teeth not spinescent or sometimes basal teeth spinescen ………….. D. moldavica 향용머리

2. Calyx inconspicuously 2-lipped. Corolla 1.5-2 long as long as calyx. $3.8-4 \mathrm{~cm}$, pubescent, middle lobe of lower lip smaller; Leaves basal cauline leaves withering early, oblong to ovate-triangular, margin riangular-dentate or sparsely serrate

D. rupestre 벌깨풀

\section{고 찰}

애기석잠풀은 멕시코 원산으로 미국의 남부지역을 포 함한 남미 일부 지역에서 확인되고 있다(Salmaki et al., 2012; González-Gallegos, 2015). 한국에 분포하는 석잠풀속 은 석잠풀, 우단석잠풀 등 4종이 알려져 있다. 본 연구에서 확인한 미기록 귀화식물인 애기석잠풀은 화관의 크기가 길이 2.4-5.2 mm로 한반도에 분포하는 석잠풀속 다른 분 류군에 비해 비교적 작다. 또한, 애기석잠풀은 소화가 6-12 개로 마디에 돌려나며, 소화의 수가 그 이하로 달리는 석잠 풀과 뚜렷하게 구별된다. 잎은 주걱형 혹은 타원형으로 길 이가 5-15 mm, 너비는 $0.8-1.2 \mathrm{~cm}$ 이고 잎 뒷면이 연한 녹색 을 띠고 있어, 잎이 피침형에 가까운 타원형으로 잎 뒷면에 짧은 회색털이 밀생하고 있는 우단석잠풀과 쉽게 구별할 수 있다. 최근까지 애기석잠풀은 멕시코와 그 주변 지역의 귀화식물로 보고되어 있었지만, 이번 조사에서 제주특별 시 서귀포시 표선면 $\left(33^{\circ} 19^{\prime} 37.5^{\prime \prime} \mathrm{N}, 1^{\circ} 6^{\circ} 48^{\prime} 58.9^{\prime \prime} \mathrm{E}\right)$ 의 경작지 주변의 초지대에서 관찰되어 한반도에서도 분포하는 것 으로 확인되었다. 국내 이입경로는 발견 장소가 제주특별 시 서귀포시 일대의 경작지 주변인 점으로 미루어 보아 재배 작물 혹은 목초의 수입과정 중 종자가 함께 유입되 었을 가능성을 추측할 수 있다. 자생지 주변은 갈퀴덩굴 [Galium spurium var. echinospermon (Wallr.) Hayek], 개구리 
발톱[Semiaquilegia adoxoides (DC.) Makino], 개사상자 [Torilis scabra (Thunb.) DC.], 양지꽃(Potentilla fragarioides var. major Maxim.), 등대풀(Euphorbia helioscopia L.) 등이 초지 식생을 이루며 혼생하여 생육하고 있었다. 2015년 제주특별시 서귀포시에서 처음 확인되었으며, 이후 처음 발견 된 지역 주변에서도 관찰되고 있어 국내에 정착하여 귀화한 것으로 판단된다. 본 식물은 짧은 기간에 넓은 지 역으로 급속하게 분포지를 넓히는 강한 번식력을 가지고 있어(Jäger and Kowarik, 2010), 잠재적인 교란의 위험이 높 을 것으로 우려되며, 주변을 중심으로 번식에 따른 분포 지 확산을 막기 위한 모니터링 등이 필요하다. 새로이 발 견된 본 분류군은 한반도에 분포하는 석잠풀에 비해 꽃의 크기가 작은 특징이 있어 '애기석잠풀'로 국명을 신칭하 였다.

향용머리는 인천시 남동구와 춘천시 신북읍 $\left(37^{\circ} 57^{\prime}\right.$ $\left.15.6^{\prime \prime} \mathrm{N}, 127^{\circ} 42^{\prime} 53.2^{\prime \prime} \mathrm{E}\right)$ 국도 주변에서 확인하였다. 본 분류 군은 중국을 중심으로 러시아 등 아시아 온대 지역에 분 포하고 있으며, 최근 북미, 오스트리아 등의 지역에 귀화 하여 분포 하는 것으로 확인되고 있다(Martínez-Vazquez et al., 2012). 한국에 분포하는 용머리속 식물은 용머리와 벌 깨풀이 있다. 이번 연구에서 새로이 발견된 향용머리는 잎이 주걱형 혹은 타원형으로 가장자리가 거치가 있어 잎 이 선형이고 전연인 용머리와 구별된다. 또한 벌깨풀은 향용머리에 비해 잎이 심장형의 넓은 원형으로 쉽게 구별 할 수 있다. 향용머리는 중국, 유럽 등에서도 원예용으로 재배되고 있거나, 약용식물로 이용되고 있으며(MartínezVazquez et al., 2012), 국내 유입은 재배식물 또는 관상용으 로 식물원이나 화원에 도입된 후 국내에 정착한 것으로 생각된다. 춘천시의 자생지에서는 국도 주변 절개지 사면 에서 개똥쑥(Artemisia anmua L.), 붉나무(Rhus javanica L.), 금방동사니(Cyperus microiria Steud.), 바랭이[Digitaria ciliaris (Retz.) Koel.], 비수리(Lespedeza cuneata G. Don), 쑥 (Artemisia indica Willd.), 자주개자리[Medicago sativa L.], 달 맞이꽃[Oenothera biennis L.], 가는털비름(Amaranthus patulus Bertol.), 개차즈기(Amethystea caerulea L.), 산국 [Dendranthema boreale (Makino) Ling ex Kitam.], 왕고들빼 기(Lactuca indica L.), 기생초(Coreopsis tinctoria Nutt.), 매듭 풀[Kummerowia striata (Thunb.) Schindl.], 차풀 [Chamaecrista nomame (Siebold) H.Ohashi], 개망초[Erigeron annuus (L.) Pers.], 박주가리[Metaplexis japonica (Thunb.) Makino], 붉은 토끼풀(Trifolium pratense L.) 등이 혼생하며, 도로주변으 로 100 여 개체 이상 확인되었다. 본 종은 종자 결실률이 높 고 종자수가 많아 분포 확산이 빠르게 진행될 것으로 생 각된다. 본 분류군은 향기가 강하게 나는 특징을 고려하 여 ‘향용머리’로 국명을 신칭하였다.

\section{사 사}

본 논문은 산림청 국립수목원 과제 특산식물 종분화 및 기원분석 연구과제(KNA1-1-13, 14-1)의 일환으로 수행되 었습니다. 자생지 정보를 제공 해 주신 강원도 자연환경 연구공원 이기홍 선생님과, 도해도를 맡아주신 조혜련 선 생님께 깊이 감사드립니다.

\section{Literature Cited}

Bhattacharjee, R. 1980. Taxonomic studies in Stachys: II. A new infrageneric classification of Stachys L. Notes from the Royal Botanic Garden, Edinburgh 38: 65-96.

Cronquist, A. 1981. An Integrated System of Classification of Flowering Plants. Columbia University Press, New York, $1262 \mathrm{pp}$.

Harley, R. M., S. Atkins, A. L. Budantsev, P. D. Cantino, B. J. Conn, R. Grayer, M. M. Harley, R. de Kok, T. Krestovkaja, R. Morales, A. J. Paton, O. Ryding and T. Upson. 2004. Labiatae. Vol 7. In The Families and Genera of Vascular Plant. Kubitzki K. (ed.), Springer, Heidelberg. Pp. 167-275.

Jäger, H. and I. Kowarik. 2010. Resilience of native plant community following manual control of invasive Cinchona pubescens in Galápagos. Restoration Ecology 18(S1): 103-112.

González-Gallegos, J. G. 2015. Stachys harkerae (Lamioideae, Lamiaceae), a new species from western Mexico. Annales Botanici Fennici 52: 345-351.

Judd, W. S., C. S. Campbell, E. A. Kellogg, P. F. Stevens and M. J. Donoghue. 2008. Plant Systematics: A Phylogenetic Approach. 3th ed. Sinauer Associates, Sunderland, MA, 620 pp.

Lee, T. B. 1999. Illustrated Flora of Korea. Hyangmunsa. Seoul, 990 pp. (in Korean)

Maríinez-Vazquez, M., R. Estrada-Reyes, A. Martínez-Laurrabaquio, C. López-Rubalcava and G. Heinze. 2012. Neuropharmacological study of Dracocephalum moldavica L. (Lamiaceae) in mice: sedative effect and chemical analysis of an aqueous extract. Journal of Ethnopharmacology 141: 908917.

Suh, Y. B., S. P. Hong and S. J. Park. 2007. Ajuga L. In The Genera of Vascular Plants of Korea. Park, C.-W. (ed.), Academy Publ. Co., Seoul. Pp. 815-819.

Salmaki, Y., S. Zarre, R. Goveaerts and C. Brächler. 2012. A taxonomic revision of the genus Stachys (Lamiaceae: Lamioideae) in Iran. Botanical Journal of the Linnean Society 170: 573-617. 